\title{
AN EXPERIMENTAL STUDY OF THE EFFECTS OF TATTOO GENRE ON PERCEIVED TRUSTWORTHINESS: NOT ALL TATTOOS ARE CREATED EQUAL
}

\author{
Dr Andrew R Timming \\ Reader in Human Resource Management \\ School of Management \\ University of St Andrews \\ St Andrews KY16 9RJ \\ Scotland \\ (art2@st-andrews.ac.uk) \\ and \\ Prof David Perrett \\ Professor of Psychology \\ University of St Andrews \\ School of Psychology and Neuroscience \\ St Mary's Quad, South Street \\ St Andrews KY16 9JP \\ Scotland \\ (dp@st-andrews.ac.uk)
}

23 January 2017

Acknowledgements: We want to thank the editor and two anonymous reviewers for useful comments. We also want to thank the participants for their time. 


\begin{abstract}
This paper examines the effects of different genres of body art on the perceived trustworthiness of hypothetical men and women with tattoos. It argues that body art is a salient cultural signal that denotes group membership and can also lead to the perception of a potential threat of harm on the part of the truster. The research finds that tattoos depicting images of violence and nudity result in the lowest levels of perceived trustworthiness; tattoos depicting images of Christianity and natural floral settings result in the highest levels of perceived trustworthiness; and the tribal tattoo genre occupies a neutral position on the trustworthiness spectrum. Whether the truster has a tattoo and shares the Christian faith with the trustee are also significant factors, as is the gender of the tattooed trustee. This paper is the first study ever to examine the effects of different genres of tattoos, thus going beyond previous research that overwhelmingly measures body art as a simple binary variable (e.g., whether or not the respondent has a tattoo).
\end{abstract}

Keywords: body art; cultural signalling; tattoos; trust; trustworthiness 


\section{INTRODUCTION}

Body modification is frequently thought of by anthropologists as an historicocultural and ritualistic phenomenon linked to ancient civilisations (Krutak, 2015), but equally it can be thought of by psychologists as a contemporary signifier of cultural identity and group membership, as will be argued in the present study. Many of the extant psychological studies on body art were carried out by scientists who examine tattoos from the perspective of evolutionary signalling, arguing that, at least for men, body art signals honest biological quality (Koziel et al, 2010) on the basis of the fact that body modification carries with it a set of well-established health risks (Stein and Nyamathi, 2004; Engel et al, 2008). In similar vein, Wholrab et al (2009) also found that tattoos displayed on men suggest honest physical fitness, as well as dominance, to potential mates. But evolutionary psychological studies such as these paint an incomplete picture of the signalling function of body art in that they fail to take account of the fact that tattoos are also powerful cultural signals that denote group membership and can potentially lead others to a perception of a threat of harm on the basis of the negative connotations that they project. Furthermore, by looking only at the effects of having a tattoo, versus not having a tattoo, many of these studies fail to understand the impact of different genres of body art (Timming, 2015) on perceived trustworthiness. The present study is the first ever to go beyond the simple dichotomous effects of having a tattoo (versus not having one) by instead examining the statistical impact of different types, or genres, of body art on perceived trustworthiness.

This research is important for at least two reasons. First, recent statistics on tattoo prevalence clearly show that body art is a significant feature of contemporary Western societies. For example, the Pew Research Center (2010) reports that 38 
percent of 18-29 year old Americans have a tattoo, 30 percent of which are described as 'visible’. A more recent survey on tattoo prevalence (Polidoro, 2014) indicates that, in 2014, 40 percent of US households reported at least one member with a tattoo; in 1999, the corresponding figure was 21 percent. Second, this research suggests that perceived trustworthiness can potentially play a vital role in any number of key life outcomes, for example, success or failure in the job market (Klotz et al, 2013) or in the quality of one’s relationship or marriage (Larzelere and Huston, 1980), as will be discussed later in this study.

In response to Möllering's (2012) call for further trust research in the creative arts, this paper uses a visual methodology to examine participants' willingness to trust hypothetical men and women displaying different genres of body art. It should be noted that the emphasis in this paper is primarily on perceived trustworthiness, rather than on actual trust, although both concepts can be said to walk hand-in-hand. Whereas the latter concept accentuates the processes through which trust is established, the former is focused primarily on impressions of trust. Taken together, trust and trustworthiness are among the most studied phenomena across the social sciences (Gambetta, 1988) and have been explored extensively in prior perception studies (DeBruine, 2002; Oosterhof and Todorov, 2009; Todorov et al, 2010; Stirrat and Perrett, 2010). Social scientists most often conceptualise trust as a rational choice (Möllering, 2001) in which the truster anticipates that the trustee will fulfil some sort of fiduciary obligation (Barber, 1983). Viewed from this angle, trust is seen through the lenses of co-operation and defection (Axelrod, 1984), often in the context of game theory (Berg et al, 1995), where the decision to trust (or not) is an important adaptive function (Williams, 1996) that assists in the processing of information with regard to who one should (and should not) interact with. 
The decision to trust, or distrust, is frequently the result of the accumulation of experiences through repeated interactions (Bó and Fréchette, 2011), but in the absence of any experiences (e.g., trust in strangers), trusters then look for (often visual) cues that suggest trustworthiness, like a high level of facial resemblance (DeBruine, 2002). Other aesthetic or visual cues to perceived trustworthiness can help to maintain a shared group membership, and thus 'common cognitions' (Lane, 2002; Timming, 2009, 2010), upon which trust can be constructed, for example, when the truster and trustee are of the same race (Simpson et al, 2007) or ethnicity (Bahry et al, 2005; Birkás et al, 2014).

The cultural meanings that are stereotypically ascribed to tattoos can also signal to the truster a perception of an increased likelihood of the trustee inflicting physical harm or injury onto others. Alternatively stated, body art can denote the possibility of physical harm in that tattoos have been traditionally associated with deviance and delinquency (Koch et al, 2010). These negative connotations, which are frequently associated with tattoos, serve as the 'mechanism' that ultimately results in a hypothesised reduction of perceptions of trustworthiness of the tattooed trustee, although no previous work has examined the ways in which different genres of body art impact on perceptions of trustworthiness.

The stereotypes that are often ascribed to body art are widely known and extensively studied. For example, tattoos have been robustly associated with any number of 'externalized risk behaviours', including, among others, illicit drug use, criminal behaviour, gang membership and a lack of impulse control (Deschesnes et al, 2006). They have also been linked empirically to an increased likelihood of carrying a weapon (Thurnherr et al, 2009) as well as to significant anger management problems (Carroll and Anderson, 2002). Although, admittedly, tattoos may not directly cause 
criminal behaviour, they are clearly and objectively associated with it (Jennings et al, 2014). From this point of view, then, tattoos can signal a perceived threat—regardless of whether or not it is real or even likely—to the truster's health and well-being based largely on stereotypical assumptions.

In this paper, we extend the literature on the effects of body art by arguing that the genre of the tattoo is an important, and hitherto under-investigated, factor that will likely impact on respondents' ratings of perceived trustworthiness of hypothetical men and women displaying tattoos. With reference to five genres of tattoos (violencethemed, nudity-themed, tribal-themed ${ }^{1}$, Christian-themed and nature-themed), we first present:

H1: Trusters rate tattoo images depicting violence and nudity lower on perceived trustworthiness than more neutral tribal tattoos, which in turn are rated lower on perceived trustworthiness than tattoo images depicting Christianity and natural floral imagery.

The rationale underlying this hypothesis is that the violence-themed images could lead, in the mind of a truster, to a perception of a threat of violence and the nuditythemed images could lead to a perception of a potential offence against the moral senses, whilst the Christian- and nature-themed images might be associated with more positive connotations that could reduce perceptions of a threat of harm; the tribalthemed images are expected to occupy a neutral territory in between. It should be noted that these assumptions, whilst speculative, are, in fact, borne out in the results of the present study.

Furthermore, we present:

H2: Trusters who are Christians rate the Christian imagery higher on perceived trustworthiness than trusters who are not Christians.

and

H3: Trusters with tattoos themselves rate the tattoo images higher on perceived trustworthiness than trusters without tattoos. 
The rationale underlying $\mathrm{H} 2$ and $\mathrm{H} 3$ is that perceived trustworthiness ratings are likely to be higher where there is a shared group membership, in this case, when the truster and trustee share body art in common and both belong to the Christian faith (Timming and Perrett, 2016).

Finally, some tentative and, as yet, emerging evidence exists suggesting that body art is viewed more negatively on women than on men (Armstrong, 1991; Swami and Furnham, 2007; Baumann et al, 2016). Moreover, it has been argued previously that the propensity to trust (or not) is itself a gendered phenomenon (Buchan et al, 2008; Bonein and Serra, 2009). Thus, we also present, albeit once again somewhat speculatively:

H4: Trusters view tattoos more negatively on females than on males.

These hypotheses are evaluated following a description of the present study's research methodology.

\section{MATERIAL AND METHODS}

Stimuli

We consulted two professional tattoo artists based in the United States prior to the experiment and asked them to identify some popular genres of tattoos. As a result of this identification process, five prominent typologies were consolidated: (i) violence-themed, (ii) nudity-themed, (iii) tribal-themed, (iv) Christian-themed and (v) nature-themed tattoos. The former two can be categorised as potentially threatening or obscene signals, the latter two as generally non-threatening signals with positive connotations and the middle one as neutral in content. The violence-themed and nudity-themed images are logically paired together because they can communicate a physical or moral threat whilst the Christian-themed and nature-themed tattoos are logically paired together because they communicate themes of love and peace. It 
should be noted that we make no claims that these five typologies are the only genres of body art worth studying, or indeed that they are the most important. We use them here only because they were identified by the tattoo artists as important genres in their profession.

One way of delivering these images in the survey instrument would be to photograph bodies displaying these five genres of tattoos, but we abandoned this idea inasmuch as ratings might then be influenced unduly by variations in placement on the body or by the physical features of the human canvas. In the end, we decided that photographs of tattoo 'flash' (images of potential tattoos that are often found in tattoo studios) would provide the best opportunity for isolating the pure effects of the tattoo images. Thus, we took four photos of each of the five genres, for a total of 20 unique images that we presented to respondents. The use of multiple images allowed for random measurement error to be cancelled out in the composites and also kept the questionnaire short enough so as to avoid significant attrition. Figure 1 displays one example of each of the five tattoo genres.

\section{Data Collection}

In total, 225 participants completed the survey instrument. All were resident in the United States of America. An instructional manipulation check (Oppenheimer et al, 2009) led to the exclusion of a few cases. Two items in the instrument were strategically placed in order to evaluate whether the participants were following directions: a simple math problem $(7+3)$ and another item that listed out 11 hobbies, but only asked respondents to select the two that begin with the letter ' $r$ ' (rugby and reading). We deleted four cases as a result of invalid responses across these two items, representing only 1.8 percent of the original sample. The final sample size is thus 221 respondents; there were no missing values. After the exclusion of these four 
cases, 52.9 percent of the sample was female, 49.3 percent Christian and the average age was 37.16 years (s.d.=12.18). The racial breakdown of the sample is 80.1 percent white, 9.0 percent black, 4.1 percent east Asian, 1.8 percent south Asian, 1.4 percent American Indian and 3.6 percent mixed race. Crucially, 31.7 percent of the sample reported having a tattoo.

Respondents completed the instrument via a popular online crowdsourcing platform and were given a nominal payment of \$0.18USD to incentivise completion of the survey. All participants provided informed consent and, as per ethics protocols, were warned a priori that the research involved viewing violent and erotic images. It is worth noting that this disclaimer may have resulted in a self-selection bias towards only those who are favourably disposed toward such images, but this limitation is obviously one that could not have been avoided for legal and ethical reasons.

The experiment unfolded over two blocks in a repeated measures design. In the first block, respondents were shown the twenty images and asked to rate how much they would trust (on a scale of 1 to 7 , where $1=$ 'extremely low trust' and 7=‘extremely high trust') a man displaying those tattoos. In the second block, the respondents were shown the same twenty images, and this time were asked to rate how much they would trust (again, on a scale of 1 to 7 , where $1=$ ='extremely low trust' and 7=‘extremely high trust') a woman displaying those tattoos. In each block, we used a random number table to randomise the presentation of the images, thus preventing respondents from identifying a pattern. Fatigue effects are highly unlikely given that the survey was, on average, completed in less than five minutes; moreover, practice effects are equally unlikely given that each block contained simple trust judgements that are not likely to 'improve' over time. At the end of the survey, we asked the participants whether they are Christians and whether they have a tattoo. 
Analysis

We employed a mixed design analysis of variance (ANOVA) as the analytical technique. The analysis was broken down by tattoo genre (violence-themed, nuditythemed, tribal-themed, Christian-themed, nature-themed), gender of the tattooed trustee (male, female), gender of the truster/ respondent (male, female), religious affiliation of truster/ respondent (Christian, non-Christian) and whether the truster/ respondent has a tattoo (no tattoo, tattoo). The latter three factors were entered into the model as between-subjects variables. Thus, we estimated a 5X2X2X2X2 mixed design model.

\section{RESULTS}

Table 1 reports the main effects of the experiment. Following Mauchly's test of sphericity (Mauchly’s W=.486) and a corresponding Huynh-Feldt correction, there was a main effect of tattoo genre $\left(F(3.01,640.95)=125.35, \mathrm{p}<.001, \eta_{\mathrm{p}}{ }^{2}=.37\right)$ where the participants rated the violence-themed images the lowest $(\mathrm{M}=2.30, \mathrm{SE}=.10)$, followed by the nudity-themed images $(M=2.96, S E=.12)$, the tribal-themed images $(M=3.38$, $\mathrm{SE}=.11)$ and the Christian-themed images $(\mathrm{M}=4.03, \mathrm{SE}=.12)$, with the nature-themed images $(\mathrm{M}=4.75, \mathrm{SE}=.09)$ found to be the most trustworthy of the five genres. Further pairwise statistics were analysed post-hoc; all Bonferroni corrected comparisons were statistically significant at the $<0.01$ level. The remaining variables in the main effects model were all statistically insignificant.

There was a significant interaction between tattoo genre and whether or not the respondent is a Christian $\left(\mathrm{F}(3.01,640.95)=15.20, \mathrm{p}<.001, \eta_{\mathrm{p}}{ }^{2}=.07\right)$, as depicted in Figure 2. Among Christians, the violence-themed tattoos were rated lowest $(M=2.20$, $\mathrm{SE}=.15)$, followed by the nudity-themed images $(\mathrm{M}=2.72, \mathrm{SE}=.17)$, the tribal-themed images $(\mathrm{M}=3.31, \mathrm{SE}=.16)$, the Christian-themed images $(\mathrm{M}=4.68, \mathrm{SE}=.18)$ and the 
nature-themed images $(\mathrm{M}=4.79, \mathrm{SE}=.14)$. Among non-Christians, the violencethemed tattoos were again rated the lowest $(\mathrm{M}=2.41, \mathrm{SE}=.13)$, followed by the nuditythemed images $(M=3.20, S E=.16)$, whilst the tribal-themed images $(M=3.45, S E=.15)$ and Christian-themed images $(\mathrm{M}=3.45, \mathrm{SE}=.17)$ were rated equally and the naturethemed images $(\mathrm{M}=4.70, \mathrm{SE}=.13)$ were rated highest. A separate independent samples t-test found that, as expected in $\mathrm{H} 2$, the Christian respondents rated the Christianthemed tattoos significantly higher $(\mathrm{M}=4.75, \mathrm{SE}=.15)$ than non-Christian respondents $(\mathrm{M}=3.54, \mathrm{SE}=.16 ; \mathrm{t}(219)=5.60, \mathrm{p}<.001,2$-tailed, equal variances assumed $)$.

There was a significant interaction between tattoo genre and whether or not the respondent has a tattoo $\left(\mathrm{F}(3.83,340.95)=3.83, \mathrm{p}=.01, \eta_{\mathrm{p}}{ }^{2}=.02\right)$, as depicted in Figure 3. Among tattooed respondents, the violence-themed tattoos were rated lowest $(\mathrm{M}=2.49, \mathrm{SE}=.17)$, followed by the nudity-themed images $(\mathrm{M}=3.20, \mathrm{SE}=.20)$, tribalthemed images $(\mathrm{M}=3.37, \mathrm{SE}=.19)$, Christian-themed images $(\mathrm{M}=3.88, \mathrm{SE}=.21)$ and nature-themed images $(\mathrm{M}=4.80, \mathrm{SE}=.16)$. Among non-tattooed respondents, the violence-themed tattoos were again rated the lowest $(\mathrm{M}=2.12, \mathrm{SE}=.11)$, followed by the nudity-themed images $(\mathrm{M}=2.72, \mathrm{SE}=.13)$, the tribal-themed images $(\mathrm{M}=3.39$, $\mathrm{SE}=.12)$, the Christian-themed images $(\mathrm{M}=4.24, \mathrm{SE}=.13)$ and the nature-themed images $(\mathrm{M}=4.69, \mathrm{SE}=.10)$. On visual inspection, Figure 3 indicates that tattooed and non-tattooed respondents may potentially rate the violence-themed, nudity-themed and Christian-themed images differently. Thus, we conducted three separate independent samples t-tests in order to evaluate these post-hoc hypotheses. A p-value cut-off of .02 was used in each t-test in order to correct for familywise error $(.05 / 3$ separate tests=.02). The only statistically significant finding is that tattooed respondents rated the nudity-based images higher $(\mathrm{M}=3.31, \mathrm{SE}=.21)$ than the non- 
tattooed respondents $(\mathrm{M}=2.73, \mathrm{SE}=.12 ; \mathrm{t}(111.06)=2.42, \mathrm{p}=.017,2$-tailed, equal variances not assumed).

Finally, there was a significant interaction between tattoo genre and trustee gender $\left(\mathrm{F}(2.78,592.90)=43.85, \mathrm{p}<.001, \eta_{\mathrm{p}}{ }^{2}=.17\right)$, as depicted in Figure 4. For tattoos that were imputed onto hypothetical men, violence-themed images were rated the lowest $(\mathrm{M}=2.50, \mathrm{SE}=.11)$, followed by the nudity-themed images $(\mathrm{M}=3.05, \mathrm{SE}=.12)$, the tribal-themed images $(M=3.51, S E=.12)$, the Christian-themed images $(M=4.13$, $\mathrm{SE}=.12)$ and the nature-themed images $(\mathrm{M}=4.39, \mathrm{SE}=.10)$. For tattoos that were imputed onto hypothetical women, the order was the same. Thus, violence-themed images were again rated the lowest $(\mathrm{M}=2.11, \mathrm{SE}=.10)$, followed by the nudity-themed images $(\mathrm{M}=2.87, \mathrm{SE}=.13)$, the tribal-themed images $(\mathrm{M}=3.25, \mathrm{SE}=.12)$, the Christianthemed images $(M=4.00, S E=.13)$ and the nature-themed images $(M=5.10, S E=.10)$. On visual inspection, Figure 4 indicates that the violence-themed images, tribalthemed images and nature-themed images may potentially vary by trustee gender; in order to test these post-hoc hypotheses, we conducted three separate paired samples ttests. Again, a .02 p-value cut-off was used in this decomposition in order to correct for familywise error. All three paired samples t-tests were statistically significant at the .001 level.

A significant three-way interaction between tattoo genre, trustee gender and truster/ respondent gender was also found $\left(\mathrm{F}(2.78,592.90)=5.32, \mathrm{p}=.002, \eta_{\mathrm{p}}{ }^{2}=.02\right)$. Additionally, a significant five-way interaction effect between tattoo genre, trustee gender, truster/ respondent gender, whether the truster/ respondent has a tattoo and whether the truster/ respondent was Christian was found $(F(2.78,592.90)=3.37$, $\mathrm{p}=.021, \eta_{\mathrm{p}}{ }^{2}=.02$ ). However, given the complexity of these interactions, they are not discussed here. The results are available upon request. 


\section{DISCUSSION AND CONCLUSIONS}

Using experimental research methods, this study sought to examine the effects of different genres of body art on the perceived trustworthiness of hypothetical men and women. We expected that tattoos would be important cultural signals that communicate group membership and a potential threat of harm to the truster. We hypothesised that some genres of body art are more likely to elicit perceptions of trustworthiness than others (H1). We also expected Christian trusters to rate Christian-themed tattoos higher on perceived trustworthiness than non-Christian trusters (H2) and that tattooed trusters would rate tattoos higher than non-tattooed trusters (H3). Finally, we expected that tattooed females would be perceived more negatively than tattooed males (H4).

The results clearly confirm H1. Both the main effects and subsequent pairwise comparisons suggest that different genres of tattoo images variably impact on perceived trustworthiness. Specifically, the violence- and nudity-themed tattoos, which potentially give the impression of a threat to physical or sexual health, were rated significantly lower than the Christian- and nature-themed tattoos, the content of which appears to neutralise to an extent the negative stereotypes that are held about tattoos in general (Carroll and Anderson, 2002; Deschesnes et al, 2006; Thurnherr et al, 2009); the tribal-themed tattoos, as expected, presented as neutral in this schemata.

The results clearly confirm H2. The Christian respondents rated the Christianthemed tattoos significantly higher than non-Christian respondents, suggesting that shared group membership and 'common cognitions' (Lane, 2002; Timming, 2009, 2010) are a cornerstone upon which trust can be built, even on the back of a medium that is widely held to have negative connotations (Timming and Perrett, 2016). However, H3 was only partially confirmed. Compared to non-tattooed respondents, 
the tattooed respondents held significantly more favourable trust dispositions toward the violence-themed and nudity-themed tattoos, but significantly less favourable trust dispositions toward the Christian-themed tattoos. The results imply that tattooed respondents are, apparently, antagonistic toward Christian-themed tattoos. This finding may be explained by the possibility that people with tattoos are simply less religious than non-tattooed people, or perhaps that tattooed people view Christianthemed tattoos as too 'mainstream'; further research is needed to corroborate.

Finally, the results partially confirm H4. Hypothetical women with violencethemed and tribal-themed tattoos were rated significantly lower on trust than hypothetical men, but hypothetical women with nature-themed tattoos were rated significantly higher on trust than hypothetical men. Thus, consistent with previous research (Armstrong, 1991; Swami and Furnham, 2007; Baumann et al, 2016), it would seem that tattoos are a potentially gendered phenomenon, with some genres being perceived as more appropriate for men than women, and vice versa.

This research makes an important and original contribution to three bodies of literature. First, it shines a new light on the extant research on cultural signalling and group membership, particularly in relation to the social psychology of body art, an emerging field of research. Previous evolutionary psychological treatments of tattoos (Koziel et al, 2010; Wholrab et al, 2009) have pointed to body modification as an honest biological signal, but the present study demonstrates that tattoos are also important cultural signifiers, or cues, that denote in-group/out-group membership and communicate non-verbally a variable likelihood of the threat of harm.

Second, this research throws a new light on virtually all of the previous studies that have looked at the effects of having a tattoo versus not having a tattoo. Whilst this is an important binary distinction, it neglects the complicated reality that each 
tattoo is a unique signifier that implies something about the character of the human canvas. Thus, studies that use standardised tattoo stimuli (e.g., Timming et al, 2015) are limited by their inability to account for the impact of the genre of the image on whatever outcome they are examining. In short, the present study casts a new light on previous research that overwhelmingly measures body art as a binary variable or construct; the effects of body art are much deeper than the question of whether or not an individual has a tattoo.

Third, the present study has implications for our understanding of the concept of perceived trustworthiness. In particular, it points to the vital importance of social identity in relation to the question of whether to extend or withhold trust (Tyler, 2001; Tanis and Postmes, 2005). Whilst trust is often established (or depleted) via repeated interactions (Bó and Fréchette, 2011), when there is no history of interaction between two or more parties, such as with trust in strangers, trusters frequently resort to visual cues in order to evaluate trustworthiness. Whether or not these visual cues provide an accurate assessment of actual trustworthiness is a wholly separate issue. This study has focused instead on perceived trustworthiness and has called attention to the role of stereotypes as potential obstacles to the establishment of trust (Foddy et al, 2009).

Although this was an online lab-based experiment, there are still a number of practical implications that can be extrapolated from the present study. Clearly, the results seem to suggest that some genres of body art are more palatable than others. This can have important implications, for example, in respect to recruitment and employee selection. More specifically, job applicants with certain genres of visible body art can, on the basis of this research, be expected to struggle to find employment, especially in jobs or roles that are customer-facing or that require a high degree of trust. Accordingly, it is important that recruiters are conscious of their own 
reactions and potential stereotypes associated with body art and take pro-active steps to overcome any latent prejudices, for example, by participating in unconscious bias training. It is also worth noting that perceptions of trustworthiness are potentially important from the point of view of relationship quality in marriages (Larzelere and Huston, 1980). Thus, it is possible that certain genres of tattoos could reduce the chances of marriage and therefore reproduction, a finding that stands in contrast with previous research (Wholrab et al, 2009; Koziel et al, 2010).

\section{Limitations and Directions for Future Research}

By way of concluding, several limitations are worth mentioning, although none are particularly devastating to the integrity of the research. Many of these limitations give rise to some useful directions for future research that can be explored.

One qualification to the argument presented in this paper is that the increased prevalence of body art in recent decades has resulted in what might be described as rapidly changing perceptions toward tattoos. For example, as more and more people get tattooed, it is arguable that the 'counter-cultural' meanings associated with body art are becoming gradually diluted. Similarly, the increased prevalence of body art may also have diminished perceptions of a potential association between tattoos and delinquency, and therefore violence. These fast-changing trends are likely to impact on trustworthiness perceptions and should be borne in mind.

Another qualification worth noting is that quantitative methods such as those used in this study are generally deficient at understanding context and meaning, both of which are better addressed using qualitative methods. Statistical and experimental studies are useful in their own right in terms of unpacking relationships, but they also often over-simplify complex phenomena such as trust and perceived trustworthiness. Although quantitative trust research has come a long way over the years and is no 
longer confined to simple measurements of trust, follow up qualitative research is nevertheless a useful path on which to move forward empirically. Such research could explore the contextual features that were absent from the present study, for example, the physical appearance of the persons displaying the tattoos and how characteristics such as attractiveness or unattractiveness (both of the human canvas and in relation to the quality of the tattoo) might play into perceptions of trustworthiness. It could also be potentially useful to explore respondents' 'global' views of tattoos in order to capture a wider picture in relation to both universal and particularistic attitudes toward body art.

There are a number of avenues that could be further explored through an extension or modification of the quantitative analytic approach used in this paper. For example, future statistical studies or experiments on the effects of tattoo genre should ask the respondents for detailed information about their own tattoos, specifically in relation to the number and types of tattoos that they have. Such information may be able to explain some of the interaction effects found in this paper. Future statistical studies might also consider examining the effect of age in an ANCOVA design. Although, in theory, the present study could have incorporated age into the model, we opted against this approach for two reasons. First, it would have made an already complex model much more complex for purposes of data interpretation. Second, it would have shifted the theoretical focus of the paper, thus making it less coherent. In addition, other key factors such as race or (non-Christian) religion could also be examined in future research. For example, it would be interesting to examine the effect of minority religions or minority races on perceived trustworthiness, although this would likely require purposive sampling in order to ensure a sufficiently large number of cases in these groups. Future research seeking to replicate the present study 
should randomise the presentation of the two experimental blocks in order to confirm that there are no order effects at play. It would also be interesting to explore the relative contribution of the factors analysed in this paper to perceived trustworthiness ratings.

Finally, we wish to draw this paper to a close with a call for more theoretical development on this topic. Whilst empirical studies such as this one certainly have intrinsic value, they should ideally be complemented with equally robust theories that seek to explain why the results were found. There may be, for example, useful social identity or cultural theories that can be brought to bear on the study of tattoo genre. Future researchers are encouraged to develop improved or alternative explanations in respect to why different genres of body art elicit variable degrees of perceived trustworthiness. In particular, further attention needs to be paid with the aim of developing the theoretical rationale underlying the hierarchy of body art genres in relation to perceived trustworthiness. 


\section{REFERENCES}

Armstrong, M.L. (1991) Career-oriented women with tattoos. Image: The Journal of Nursing Scholarship, 23, 215-220.

Axelrod, R. (1984) The Evolution of Cooperation. New York: Basic Books.

Bahry, D.; Kosolapov, M.; Kozyreva, P. and Wilson, R.K. (2005). Ethnicity and trust: Evidence from Russia. American Political Science Review, 99, 521-532.

Barber, B. (1983) The Logic and Limits of Trust. New Brunswick: Rutgers University Press.

Baumann, C.; Timming, A.R. and Gollan, P. (2016) Taboo tattoos? A study of the gendered effects of body art on consumers' attitudes toward visibly tattooed front line staff. Journal of Retailing and Consumer Services, 29, 31-39.

Berg, J.; Dickhaut, J. and McCabe, K. (1995) Trust, reciprocity, and social history. Games and Economic Behavior, 10, 122-142.

Birkás, B.; Dzhelyova, M.; Labádi, B. and Perrett, D.I. (2014) Cross cultural perception of trustworthiness: The effect of ethnicity features on evaluation of faces' observed trustworthiness across four samples. Personality and Individual Differences, 69, 56-61.

Bó, D.P. and Fréchette, G.R. (2011) The evolution of cooperation in infinitely repeated games: Experimental evidence. American Economic Review, 101, 411-429.

Bonein, A. and Serra, D. (2009) Gender pairing bias in trustworthiness. Journal of Socio-Economics, 38, 779-789.

Buchan, N.R.; Croson, R.T.A. and Solnick, S. (2008) Trust and gender: An examination of behavior and beliefs in the Investment Game. Journal of Economic Behavior and Organization, 68, 466-476.

Carroll, L. and Anderson, R. (2002) Body piercing, tattooing, self-esteem, and body investment in adolescent girls. Adolescence, 37, 627-637.

DeBruine, L.M. (2002). Facial resemblance enhances trust. Proceedings of the Royal Society B: Biological Sciences, 269, 1307-1312.

Degelman, D. and Price, N.D. (2002) Tattoos and ratings of personal characteristics. Psychological Reports, 90, 507-514.

Deschesnes, M.; Fines, P. and Demers, S. (2006) Are tattooing and body piercing indicators of risk-taking behaviours among high school students? Journal of Adolescence, 29, 379-393. 
Engel, E.; Santarelli, F.; Vasold, R.; Maisch, T.; Ulrich, H.; Prantl, L. et al (2008) Modern tattoos cause high concentrations of hazardous pigments in skin. Contact Dermatitis, 58, 228-233.

Foddy, M; Platow, MJ and Yamagishi, T (2009) Group-Based Trust in Strangers: The Role of Stereotypes and Expectations. Psychological Science, 20, 419422.

Gambetta, D. (1988) (ed) Trust: Making and Breaking Cooperative Relations. Oxford: Basil Blackwell.

Jennings, W.G.; Hahn Fox, B. and Farrington, D.P. (2014) Inked into crime? An examination of the causal relationship between tattoos and life-course offending among males from the Cambridge study of delinquent development. Journal of Criminal Justice, 42, 77-84.

Klotz, A.C.; da Motta Veiga, S.P.; Buckley, M.R. and Gavin, M.B. (2013) The role of trustworthiness in recruitment and selection: A review and guide for future research. Journal of Organizational Behavior, 34, S104-S119.

Koch, J.R.; Roberts, A.E.; Armstrong, M.L. and Owen, D.C. (2010) Body art, deviance, and American college students. Social Science Journal, 47, 151-161.

Koziel, S.; Kretschmer, W. and Pawlowski, B. (2010) Tattoo and piercing as signals of biological quality. Evolution and Human Behavior, 31, 187-192.

Krutak, L. (2015) The cultural heritage of tattooing: A brief history. Current Problems in Dermatology, 48, 1-5.

Lane, C. (2002). Introduction: Theories and issues in the study of trust. In Trust within and between Organizations (ed C. Lane and R. Bachmann). Oxford: Oxford University Press, 1-30.

Larzelere, R.E. and Huston, T.L. (1980) The Dyadic Trust Scale: Toward Understanding Interpersonal Trust in Close Relationships. Journal of Marriage and Family, 42, 595-604.

Möllering, G. (2001). The nature of trust: From Georg Simmel to a theory of expectation, interpretation and suspension. Sociology, 35, 403-420.

Möllering, G. (2012) Trusting in art: Calling for empirical trust research in highly creative contexts. Journal of Trust Research, 2, 203-210.

Oosterhof, N.N. and Todorov, A. (2009). Shared perceptual basis of emotional expressions and trustworthiness impressions from faces. Emotion, 9, 128-133.

Oppenheimer, D.M.; Meyvis, T. and Davidenko, N. (2009) Instructional manipulation checks: Detecting satisficing to increase statistical power. Journal of Experimental Social Psychology, 45, 867-872. 
Pew Research Center. (2010) Millenials: A Portrait of Generation Next [Report accessed 3 January 2013 at www.pewsocialtrends.org/files/2010/10/millenials -confident-connected-open-to-change.pdf].

Polidoro, R. (2014) Infographic: America’s love for tattoos grows. NBC News/Wall Street Journal Poll. [Article accessed 29 July 2014 at www.nbcnews.com/ nightly-news/infographic-americas-love-tattoos-grows-n95486].

Simpson, B.; McGrimmon, T. and Irwin, K. (2007). Are blacks really less trusting than whites? Revisiting the race and trust question. Social Forces, 86, 525552.

Stein, J.A. and Nyamathi, A. (2004) Correlates of Hepatitis C Virus infection in homeless men: A latent variable approach. Drug and Alcohol Dependence, 75, 89-95.

Stirrat, M. and Perrett, D.I. (2010). Valid facial cues to cooperation and trust: Male facial width and trustworthiness. Psychological Science, 21, 349-354.

Swami, V. and Furnham, A. (2007) Unattractive, promiscuous and heavy drinkers: Perceptions of women with tattoos. Body Image, 4, 343-352.

Tanis, M and Postmes, T (2005) A social identity approach to trust: Interpersonal perception, group membership and trusting behaviour. European Journal of Social Psychology, 35, 413-424.

Thurnherr, J.; Michaud, P.A.; Berchtold, A.; Akré, C. and Suris, J.C. (2009) Youths carrying a weapon or using a weapon in a fight: What makes the difference? Health Education Research, 24, 270-279.

Timming, A.R. and Perrett, D. (2016) Trust and mixed signals: A study of religion, tattoos and cognitive dissonance. Personality and Individual Differences, 97, 234-238.

Timming, A.R.; Nickson, D.; Re, D. and Perrett, D.I. (2015). What do you think of my ink? Assessing the effects of tattoos on employment chances. Human Resource Management. (Early View).

Timming, A.R. (2015) Visible tattoos in the service sector: a new challenge to recruitment and selection. Work, Employment \& Society, 29, 60-78.

Timming, A.R. (2009). Trust in cross-national labour relations: a case study of an Anglo-Dutch European works council. European Sociological Review, 25, 505-516.

Timming, A.R. (2010). Dissonant cognitions in European works councils: A "comparative ethnomethodological” approach. Economic and Industrial Democracy, 31, 521-535.

Todorov, A.; Loehr, V. and Oosterhof, N.N. (2010) The obligatory nature of holistic 
processing of faces in social judgments. Perception, 39, 514-532.

Tyler, TR (2001) Why do people rely on others? Social identity and social aspects of trust. In Trust in Society (edited by KS Cook). New York: Russell Sage Foundation, pp. 385-306.

Wholrab, S.; Fink, B.; Kappeler, P.M. and Brewer, G. (2009) Perception of human body modification. Personality and Individual Differences, 46, 202-206.

Williams, G.C. (1996) Adaptation and Natural Selection: A Critique of Some Current Evolutionary Thought. Princeton: Princeton University Press. 
Figure 1: Examples of Tattoo Genre Images (Violence, Nudity, Tribal, Christian and Nature)
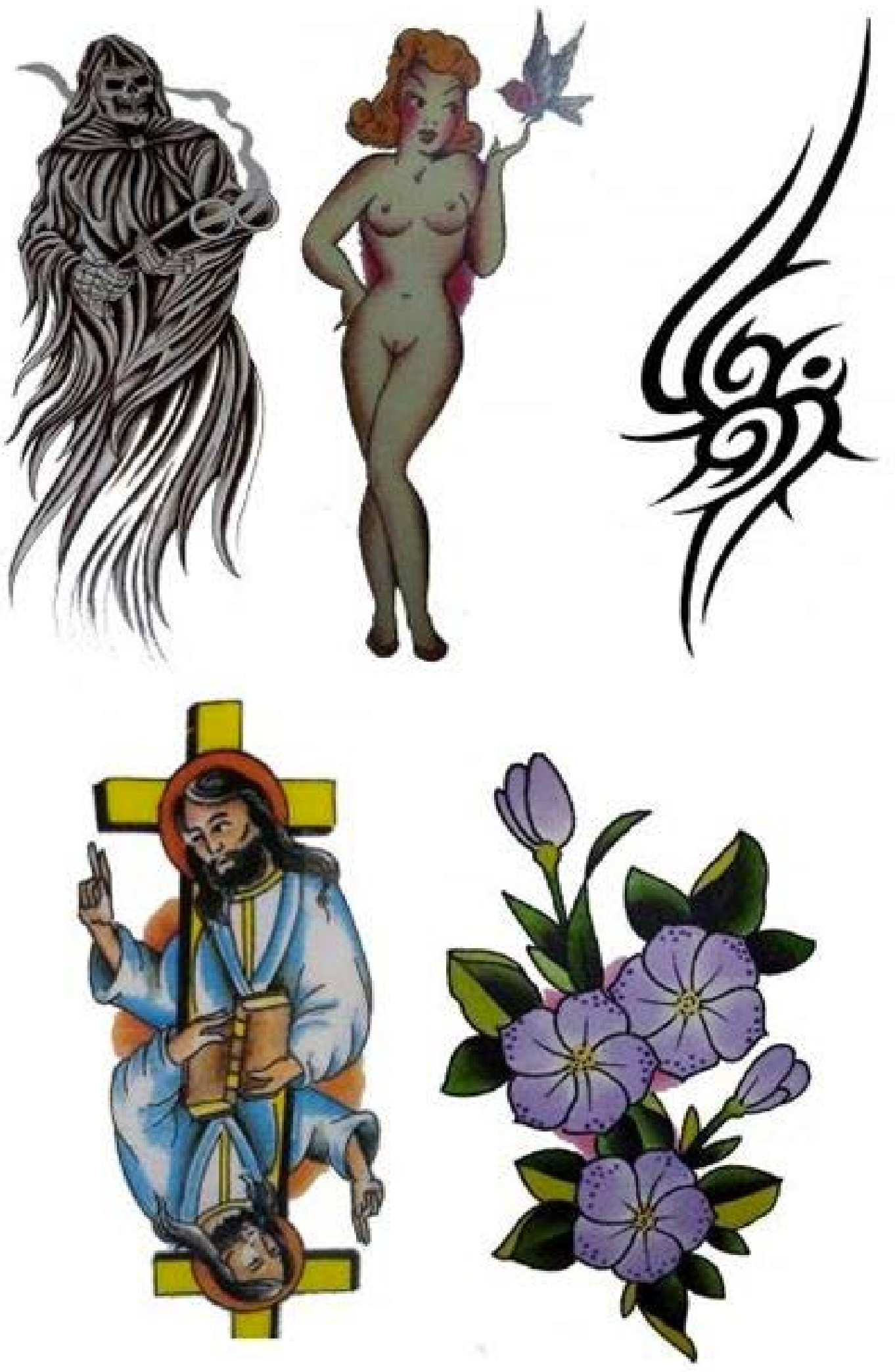


\begin{tabular}{|c|c|c|c|c|c|c|}
\hline & Effect type & Mean rating (SE) & Mean rating difference & $\mathbf{F}$ & $\mathbf{p}$ & $\eta_{p^{2}}^{2}$ \\
\hline $\begin{array}{c}\text { Tattoo Genre } \\
\text { (Violence; Nudity; } \\
\text { Tribal; Christian, } \\
\text { Nature) }\end{array}$ & Within-subjects & $\begin{array}{c}\text { Violence: } 2.30(0.10) \\
\text { Nudity: } 2.96(0.12) \\
\text { Tribal: } 3.38(0.11) \\
\text { Christian: } 4.03(0.12) \\
\text { Nature: } 4.75(0.09)\end{array}$ & $\begin{array}{c}\text { Nudity-Violence }=0.66 \\
\text { Tribal-Violence }=1.08 \\
\text { Christian-Violence }=1.73 \\
\text { Nature-Violence }=2.45\end{array}$ & 125.35 & $<.01$ & .37 \\
\hline $\begin{array}{l}\text { Trustee Gender } \\
\text { (male; female) }\end{array}$ & Within-subjects & $\begin{array}{c}\text { Male: } 3.52(0.08) \\
\text { Female: } 3.47(0.08)\end{array}$ & 0.05 & 1.93 & .17 & .01 \\
\hline $\begin{array}{l}\text { Truster Gender } \\
\text { (male; female) }\end{array}$ & Between-subjects & $\begin{array}{c}\text { Male: } 3.40(0.12) \\
\text { Female: } 3.58(0.10)\end{array}$ & -0.18 & 1.26 & .26 & .01 \\
\hline $\begin{array}{c}\text { Truster Religion } \\
\text { (Christian; not } \\
\text { Christian) }\end{array}$ & Between-subjects & $\begin{array}{c}\text { Christian: } 3.54(0.12) \\
\text { Not Christian: } 3.44(0.11)\end{array}$ & 0.10 & 0.41 & .52 & $<.005$ \\
\hline $\begin{array}{l}\text { Truster Tattoo } \\
\text { (tattoo; no tattoo) }\end{array}$ & Between-subjects & $\begin{array}{c}\text { Tattoo: } 3.55(0.13) \\
\text { No tattoo: } 3.43(0.08)\end{array}$ & 0.12 & 0.57 & .45 & $<.005$ \\
\hline
\end{tabular}


Figure 2: The effect of Christian faith on trust judgements attributed to bearers of tattoos of different genres. Christians viewed Christian tattoos more favourably than non-Christians. Mean and standard error of judgements are displayed.

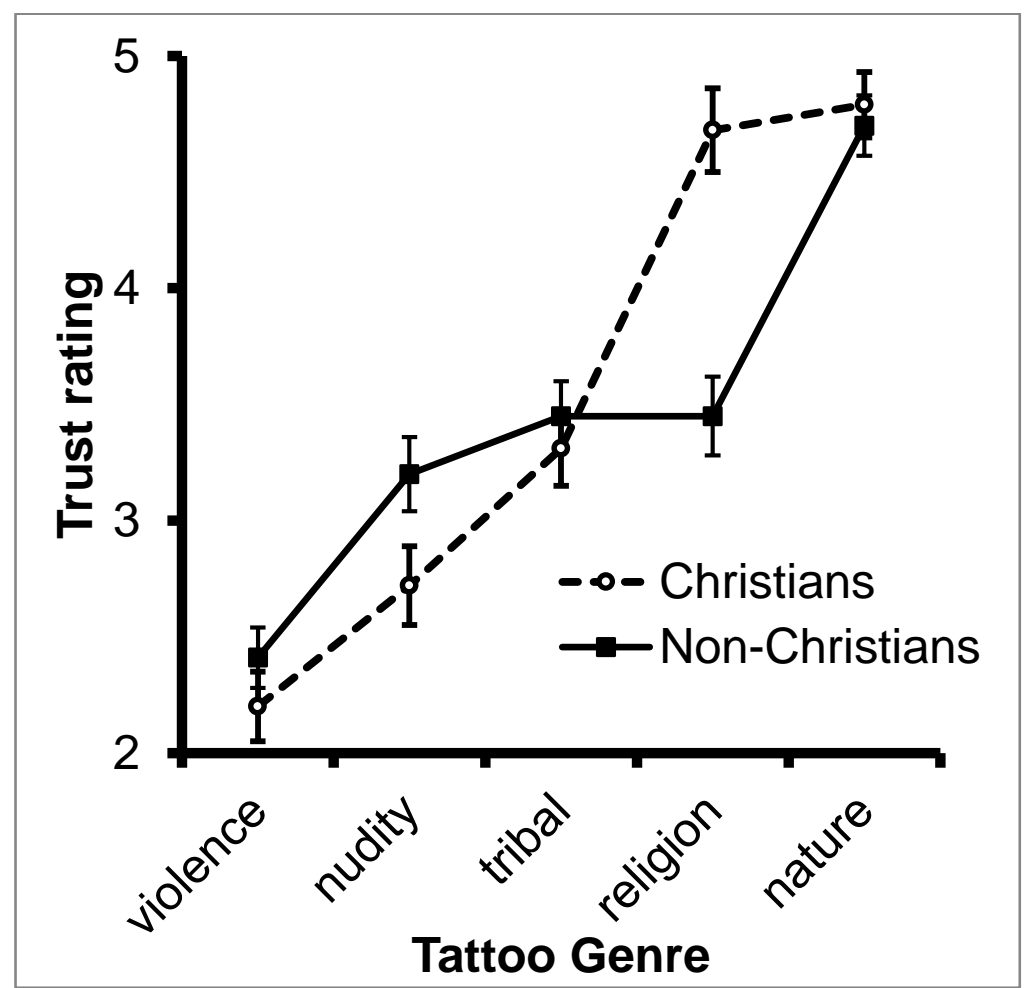


Figure 3: The effect of respondents having a tattoo on their trust judgements of different genres of tattoo. Tattooed respondents responded more favourably to violence and nudity tattoo themes than non-tattooed respondents; yet showed the opposite pattern for Christian themes. Mean and standard error of judgements are displayed.

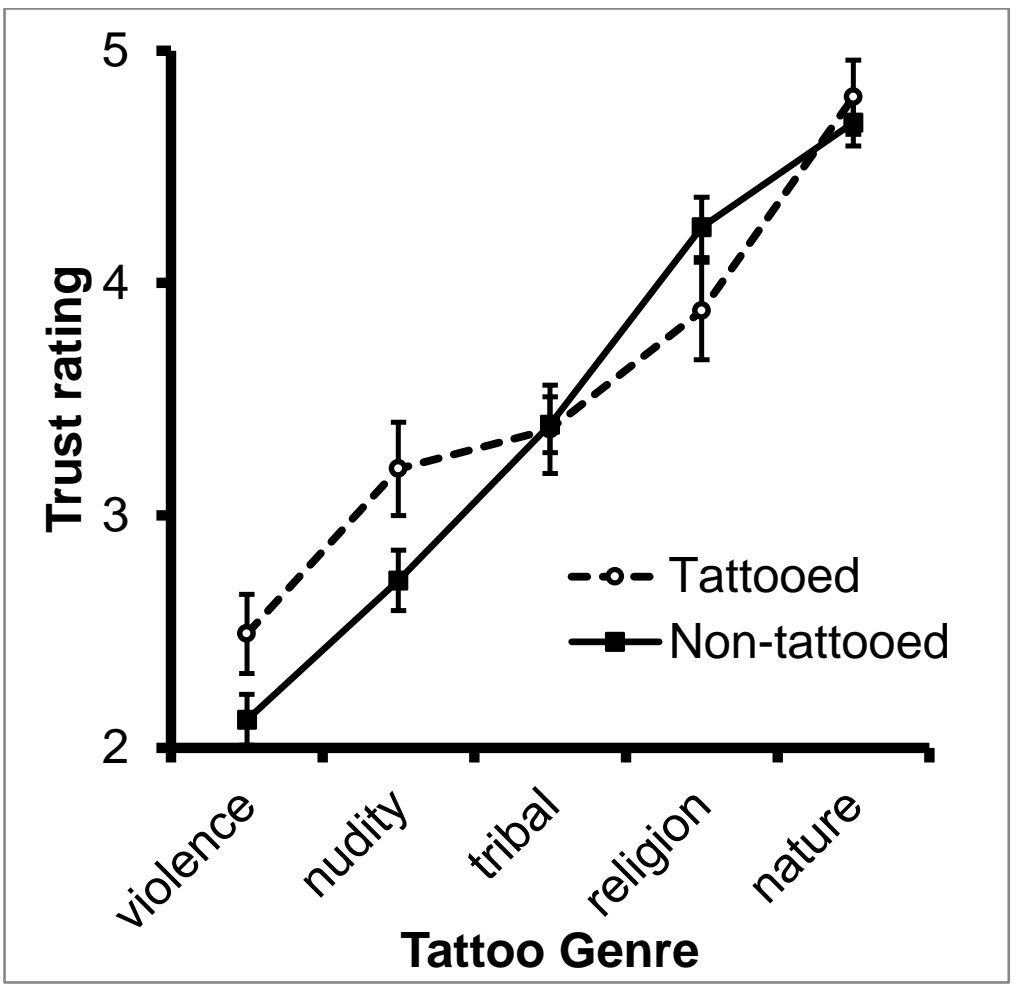


Figure 4: The effect of gender imputed to tattoo owner on trust judgements.

Women with most genres of tattoo were trusted less than men, yet women with nature themed tattoos were trusted more than men with the same nature theme-tattoos.

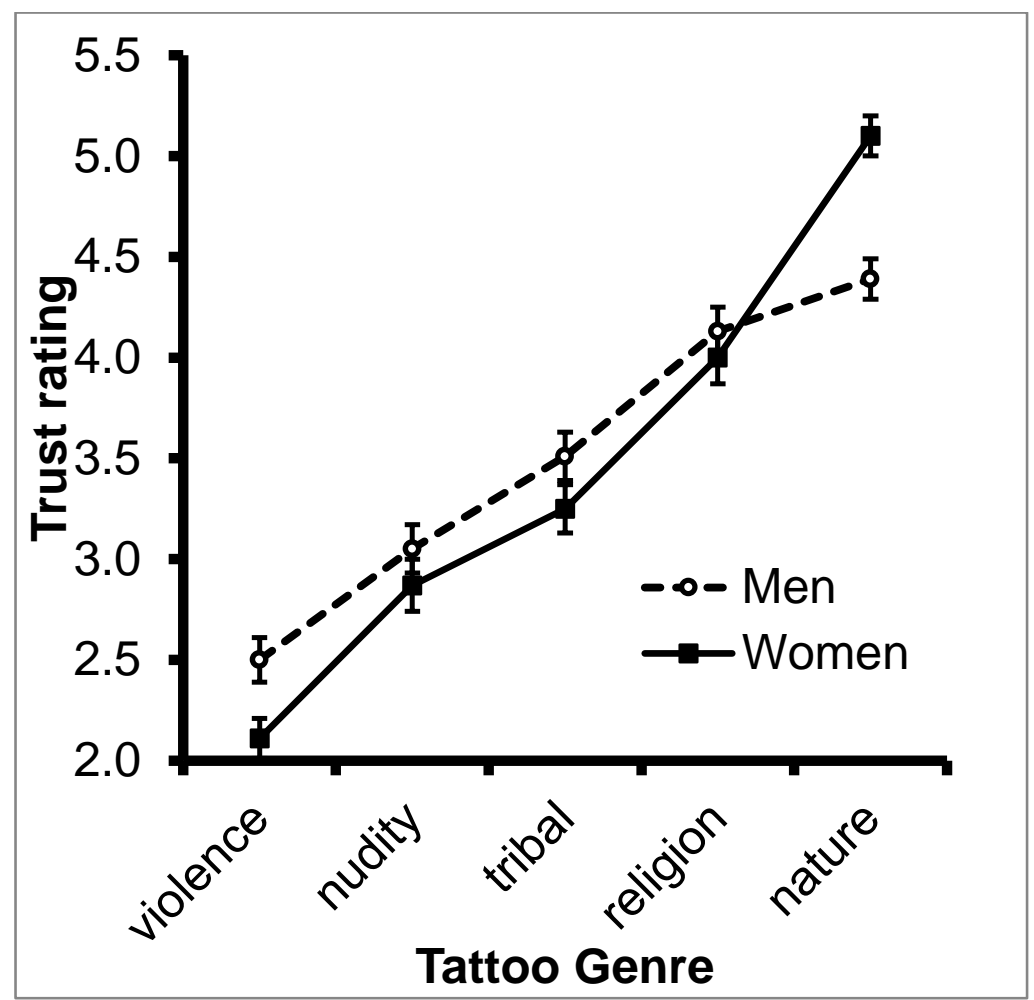


1 Tribal tattoos are mainly black designs that are characteristic of the indigenous Maori tribes of New Zealand, but that have become popular among Western young adults. 